\title{
Title: Postgraduate work-based learning: a qualitative study
}

\begin{abstract}
Purpose - This paper explores the experiences of students and teachers who had participated in a postgraduate work-based praxis course within a Master of mental health practice qualification.

Design/methodology/approach - This qualitative study used an interpretative phenomenological approach to understand the lived experience of students and course convenors participating in a work-based praxis course. Seven students and two convenors were recruited. Interview and reflective portfolio data were analysed thematically.

Findings - The main themes identified were the importance of planning, the value of partnerships, the significance of learning in the workplace, and how the facilitation of workbased learning differs from coursework.
\end{abstract}

Originality/value - Work-based learning within postgraduate coursework qualifications can support higher-level learning, knowledge and skills. . This study supported the value of providing postgraduate students with work-based learning opportunities, resulting in the application of new or advanced skills, within their existing work roles. This study is important, because it provides insights into the student experience of postgraduate workbased learning and the impact of this learning on professional practice.

Keywords - Postgraduate, work-based learning, praxis, mental health, workforce Paper type - Research 


\section{Introduction}

Australia's mental health sector is undergoing intense reform, reflecting changes in the way that mental health services are being delivered and the complexity of the consumers accessing these services (Roberts and Maylea, 2017). Due to the significant social and emotional costs of poor mental health, Governments are focusing on mental health workforce development, education and training to improve quality of care for those experiencing mental illness (Hewlett and Moran, 2014). Research has identified that many health professionals enter the workforce with inadequate skills to practise in mental health settings and undergraduate health education programs vary in quantity and quality of mental health knowledge and skill development (Happell, 2006, Council of Australian Governments, 2009). In addition, advances in technology, well-educated and informed consumers, and expanding requirements for ongoing professional registration and service innovation, are shifting the way health practitioners participate in continuing education (Higgs et al., 2010, Eikeland, 2013). Within this context, there is consensus that undergraduate education is only the beginning of professional learning and recognition that continuing, and specialised, professional development is essential to meet changing health workforce requirements. As a result, higher education institutes (HEIs) are attempting to address this gap through the provision of postgraduate qualifications in mental health practice (Jarvis, 2009, McCrae et al., 2014, Stewart et al., 2016b).

To meet the development needs of mental health practitioners, Griffith University in Queensland, Australia, introduced postgraduate mental health practice qualifications (Graduate Certificate and Masters qualification) in 2009. These qualifications provide practitioners from a range of professional backgrounds with the knowledge and skills in mental health practice and respond to emerging workforce needs (Stewart et al., 2012). Health education literature suggests that course-based programs are relatively ineffective strategies for learning within complex health care systems, producing at best only small changes in clinical practice (Forsetlund et al., 2009, Pype et al., 2014). Following an evaluation of two postgraduate mental health qualifications in 2011, a work-based course (praxis) was introduced in the Masters qualification to promote learning in, and from, the workplace, with learning goals derived from workplace and student needs (Stewart et al., 2016a). Within nursing literature, praxis describes the process of knowledge and practice being remade through ongoing reflection within action; and it is for this reason praxis was the title given to this course (McCormack and Manly, 2004). 
Boud and Solomon defined work-based learning as the process whereby HEIs and workplaces create new learning opportunities within the work being undertaken (Boud and Solomon, 2001). The praxis course utilised this approach with a focus on developing a curriculum that emphasised learning in work. Within workplaces, students were engaged in authentic work activities and interactions that determined learning needs, and provided both the context and occurrences of learning (Zhang et al., 2016). Work-based learning has been recognised as a process that improves the application of knowledge to practice and contributes to the development of self-directed students who better able to meet the challenges within service delivery (Rhodes and Shiel, 2007, Lester and Costley, 2010). It is an important method of upskilling health professionals, as learning is practice-driven and enables practitioners to recognise and value their ability to adopt new ways of working (Spouse, 2001). Rather than workplace learning occurring incidentally, it can be highly structured, deliberate, and central to the needs of both the workplace and practitioner (Billett, 2004). The structuring of workplace activities can in themselves have pedagogic practices, shaping how individuals think-act-learn through action (Billett, 2002, Lester and Costley, 2010).

Evaluations of work-based learning programs suggest that they can provide effective opportunities for personal and professional growth, in addition to addressing specific workplace issues (Gruppen et al., 2012). Students acknowledge benefits such as gaining skills, expertise, and confidence, opportunities to reflect on and better understand workplace issues, and inspiration to pursue further learning and development (Costley and Stephenson, 2008). Employers have identified positive outcomes for workers such as, improved work efficiency, increased ability to undertake more demanding roles, and acknowledgement from colleagues of the expertise and resources within the work team (Costley and Abukari, 2010). The combination of independence in learning and the opportunity to focus on relevant practice issues supported and encouraged by employing organisations, can provide powerful learning opportunities (Clarke and Copeland, 2003). This form of learning is well suited to postgraduate students seeking to improve their professional practice and acquire expertise or advanced practice skills.

To ensure appropriate work-based learning, however, it is important to develop pedagogies that recognise the workplace as a legitimate learning environment and provide guidelines for how best to structure and evaluate learning initiatives (Nottingham, 2016). For postgraduate students, it is particularly important that learning is negotiated and derived from the needs of the student and the workplace, rather than the traditional disciplinary curriculum which 
currently dominates most pre-work education (Garnett, 2016). Praxis, as a form of work-based learning, is truly student-focussed, requiring the engagement of students in both identifying and planning their learning activities (Kettle, 2013). Practitioners need to be prepared to learn and implement new practices, and to do this successfully, they need to know how to learn. Work-based pedagogy needs to respond by emphasising a more self-directed and selfdetermined approach, in which learners are able to reflect on what is learnt and how it is learnt, with educators focussing on teaching learners how to advance their own learning (Blaschke, 2012). Within HEIs, work-based learning opportunities span a continuum from initial professional development through to collaborative learning within workplaces, formally recognising learning that takes place in, through and for work (Bravenboer, 2018; Lester, Bravenboer and Webb, 2016). It is essential that HEIs recognise the complexities of workbased learning and adopt practices that support this new approach to learning (Costley and Abukari, 2015)This study contributes to work-based learning knowledge by undertaking a qualitative study exploring the experiences of those who had participated in a postgraduate praxis course within a Master of mental health practice qualification. By capturing in-depth descriptions of their experiences, this study investigated how work-based learning contributed to student learning, work performance and workplace practices. The study also provided insights into the possible opportunities and challenges with implementing the program into other settings.

\section{Methods}

\section{Study design}

The overall aim of this study was to explore the experiences of participants who had completed the praxis course. A qualitative approach was utilised, specifically an interpretative phenomenological approach (IPA). Interpretative phenomenology seeks to gather in-depth descriptions of a participant's experiences with the aim of determining the meaning of these experiences (Smith et al., 2009). A primary activity within IPA is researcher reflection on the data to capture the 'essence' of the participant experience (Saldana, 2011), whilst utilising processes and approaches (e.g. reflexivity and acknowledgement of biases) to integrate the researcher's own experiences and assumptions into the data collection and data analysis phases (Smith et al., 2009). As the researcher had been involved in the development and teaching of the praxis course, it was recognised that there would be shared aspects and understandings of 
the phenomenon (the experience of the praxis course). IPA provided an approach that integrated both researcher and participant understandings.

\section{Data collection}

Students enrolled in the praxis course $(n=12)$ and praxis course convenors $(n=2)$ in Semester 2 (2013) and Semester 2 (2014) were invited to participate in a semi-structured telephone interview. A flexible interview schedule was developed and piloted with two academic colleagues and two former students. The interview schedule consisted of six open-ended questions (Table 1) intended to obtain detailed accounts of praxis experiences. Verbal consent for participation and audio-recording of interviews was obtained prior to each telephone interview; these were conducted by the same researcher and lasted between 35 and 55 minutes (average 48 minutes). A verbatim transcript of the interview was emailed to each participant to ensure the written narrative accurately described the conversation; no alterations were requested. Additional data were obtained by the inclusion of student reflective portfolios, which provided written reflections on individual experiences and episodes of learning, as well as ideas regarding how future practice may be influenced by these learnings.

\section{INSERT TABLE 1 HERE}

\section{Data analysis}

Analysis using an IPA approach aims to make sense of participant experiences via a process of coding, organising, integrating and interpreting data (Smith et al., 2009). The four analytical steps, recommended by Smith et al. (2009), were utilised in the analysis and included: i) multiple readings and note-taking; ii) transforming notes into emerging themes; iii) seeking relationships and clustering themes; and iv) linking to produce a final set of themes.

All interview transcripts and portfolio documents were carefully read by the researcher several times and were entered into NVivo ${ }^{\odot} 11$ computer software (Qualitative Solution and Research, 2011) for coding. Once an overall sense of the complete data set had been achieved, each individual transcript and portfolio was reviewed, noting the researcher thoughts, observations and reflections in annotations and memos. Transcripts for the first five interviews were separately analysed by an independent researcher (an academic colleague), and discussions between the two researchers questioned interpretive comments and compared and contrasted emerging themes to establish a clear audit trail. Discussions continued until consensus on a set 
of themes was identified and validity of the emerging themes was examined during the analysis of the remaining texts.

\section{Results}

Seven of the 12 work-based students (Table 2) and both praxis convenors approached, agreed to participate in an interview. At the time of interview, all students were working in mental health services. Each participant was given a pseudonym when presenting results to ensure confidentiality.

\section{INSERT TABLE 2 HERE}

Both convenor participants (Rachel \& Grace) were female, aged 45 and 52 years, and had health professional backgrounds. Rachel had over 20 years' experience as a social worker, and at the time of the interview held a senior position at a large teaching hospital. She was undertaking the praxis course convenor role for the first time. Grace had a background in psychology, with many years' experience in academia including previous roles in convening the praxis course.

Thematic analysis identified three main themes and several subthemes describing different aspects of the praxis experience (Table 3 ).

\section{INSERT TABLE 3 HERE}

\section{Planning for work-based learning is hard but important}

This theme describes the discomfort and anxiety experienced by students as they developed their initial praxis learning plans. Students reported that the planning process was stressful, and developing the plan took considerable time and thought, requiring support from the course convenor.

The journey from resistance to celebration

Students expressed early misgivings regarding the relevance and applicability of the praxis course, and were initially unsure how work-based learning would support their practice. Many students had difficulty envisaging how they could achieve learning outcomes in their own workplaces and initially voiced preferences for, and familiarity with, coursework. 
I thought, what new things can I learn in the workplace and how is that going to work in my role? So, my first thoughts were apprehensive, not very confident that it's going to be effective, and I think I was a bit negative, honestly. (Emma - student)

\section{Difficulty deciding on a goal}

Deciding on appropriate work-based learning goals and developing their learning plan was a new experience for students, requiring them to extend their thinking from current roles and professional practices to explore how these could be changed or enhanced. For many students, structuring their ideas and settling on clear and measurable goals that were achievable within the course timeframe was a difficult task. Goals were generally selected through relevance to their work and professional interests, although many struggled to identify and describe workbased activities which would develop their practice skills. In addition, recognising or articulating when outcomes or practice changes had been achieved was problematic for many. Praxis convenors agree with students:

The learning plan is the thing that they struggle with the most, that's for sure. I think supervisors and students are really good at talking about some ideas, broadly, about what they could learn or do, but the learning plan tries to make it more structured and outcome focussed and looking at the evidence of their learning. [The students] really struggle with that. (Grace - convenor)

Praxis convenors reported that assisting students to reflect and focus on developing their professional practice and goals for the future required specific skills. Previous experience in counselling, motivational interviewing, goal setting and supervision were identified as important skills needed to support students with the development of their praxis learning goals and plans. Supportive communication with convenors or workplace supervisors/mentors assisted students to understand the praxis process and finalise their learning goals and activities:

When I contacted [the course convenor], they had a look at [my initial learning plan] and sent it back. And then we had a discussion on the phone and they gave me a lot of good pointers and ideas on how to expand my praxis goals and activities and to be able to clarify [my learning outcomes] a bit better. (Natalie - student)

Due to the individualised nature of the learning plans, both praxis convenors expressed concern about how learning effort and outcomes were assessed. Recognising quality outcomes and standards of learning, as well as ensuring that students engaged in similar levels of effort 
throughout the praxis course were identified issues. The praxis process was seen as very different to coursework learning, which generally has more structured processes and criteria against which to measure outcome/s. Convenor's reflections suggested an attempt to reproduce familiar coursework practices into the unfamiliar, and complex, praxis setting:

Because I had high expectations about what people would produce, I'm still not sure that [the students] all gave me a level that I would expect ... [We need] standardising about our expectations and what [students] should be able to achieve, and then some standardising on learning plans and learning efforts. (Rachel - convenor)

As the praxis course was situated within a postgraduate, coursework, qualification many students struggled to engage in this new way of learning.

\section{Planning is the key to success}

Although difficult, all students recognised that the learning plan, built on their specific learning goals, was an important element in structuring their praxis experience and ensuring that learning occurred. Transforming ideas into step-by-step activities and providing structure, focus and motivation for learning activities, was an important aspect of the plan:

I liked writing a plan because when you think of an idea, you can then break it down into steps. I looked at it and thought, well yeah, I can do this now. I would say [the learning plan was] very useful because it was something that I could come back to and think, well that's what I want to achieve and that's how I'm going to get there, so that's what I'm going to do at this point in time. (Chloe - student)

Students acknowledged that as well as providing structure, the learning plan assisted in maintaining their motivation and focus on the learning activities. The plan allowed a shared understanding of goals, workplace contexts and a process to monitor progress:

I think it could be easy for people just to drift back to same old same old, so actually having set skills and knowledge that the students are going to be focussed on and show how they've achieved, keeps them more on task. (Grace - convenor)

Due to the self-directed nature of work-based learning, a number of students commented on the need to keep reminding themselves to prioritise the praxis activities, to work independently and remain committed to their self-identified goals: 
I think that because there's not so much structure to do the praxis, you have to be really self-motivated, like choosing what you want to do and then doing it yourself. There's not someone checking up on you every day. (Chloe - student)

\section{The significance of learning in the workplace}

Work-based learning was seen as noticeably different from coursework learning. Providing an opportunity to reflect upon current work and professional practice was appreciated by students, with a number commenting on the importance of incorporating this into their future practice.

\section{Time for reflection}

Time and space to reflect upon professional practice was recognised as an important aspect of work-based learning. Students valued the opportunity to review their practice, identifying areas of need and reflecting upon the quality of services they were providing to mental health consumers. The praxis process was also seen as important in recognising and planning for ongoing professional learning and career development.

\section{Learning requires partnerships}

The strengths gained through in learning together were articulated by both students and convenors. The importance of mentors, supervisors, colleagues, academic staff and mental health consumers in the learning process was acknowledged, and through these partnerships, change and transformation were achieved. A number of students acknowledged the learning that had occurred through reviewing or questioning routine practice:

Regular supervision sessions [with my workplace supervisor] enabled me to monitor my development and identify further needs ... One example of this happened during a team meeting in which disagreement occurred regarding the assessment of youth referrals. In [resolving] this case, my concerns helped in identifying a learning need for all clinicians in the team. (Emma - student)

As well as reviewing practice with others, students reported that stepping outside their usual roles and practices into a learning or student role was a powerful tool. This element of the praxis course enabled students to be curious and ask questions of themselves and others. Opening discussions with others as a student, rather than in their usual health practitioner role, provided opportunities for different types of conversations with colleagues and the consumers they worked with, resulting in ongoing changes in team communication and processes: 
I think what helped in my learning, was being a student. When I said I was a student to my colleagues, particularly when you've worked in a job for many years, you're actually seen as the expert, I suppose, or the professional, it's actually quite nice to take a student role and be able to ask colleagues for their input and their expertise, and to not be kind of all-knowing. (Emma - student)

The support received from the workplace, both management and colleagues, was identified as an important element impacting on both the planning process and how students undertook their learning activities. As well as relationship-building within individual workplaces, many of the praxis learning activities involved the need to create partnerships with external organisations. Students were able to discern value for their practice in developing these new relationships and saw the praxis as an opportunity to connect their organisation to other organisations and further develop their professional networks.

\section{Positive end results}

All participants were able to acknowledge positive outcomes, including new knowledge, skills, practices, and confidence, which were achieved through their participation in work-based learning. In addition, new roles and positions, recognition for skills and expertise, and opportunities to widen service provision and cooperate with other organisations, were all reported outcomes. The opportunity to integrate practice and theory within a work setting and a focus on outcomes that were applied within professional practice were identified as strengths of the praxis course.

\section{The academic side of the story}

This theme explores participants' perspectives regarding interactions and processes of workbased learning situated within the higher education system.

\section{Isolation and the impact of on-line study}

Both convenor and student participants identified unique challenges in participating in workbased learning through an on-line environment. Finding the right balance of frequency and method of contact was important for each individual student, supervisor and workplace. As well as contact from the praxis convenors, a number of students reported that limited contact with other student peers led to feelings of isolation.

Ensuring safety 
During the praxis course, a number of students experienced times of stress in response to significant events occurring within the workplace (e.g., death of clients, undergoing organisational change). Praxis convenors reported that providing support to ensure the safety and wellbeing of students was important and their counselling and clinical backgrounds facilitated effective support.

\section{Skills of the praxis convenor}

Communication skills and the ability to manage relationships were regarded as important attributes for the praxis convenor; a background in counselling was seen as helpful. Previous work within the mental health field facilitated an understanding of different practice settings and professional practice requirements. Convenors identified that teaching the praxis course was a time-intensive process, not fully acknowledged or resourced by the university.

\section{Discussion}

Overall, the findings from this study are consistent with the body of evidence supporting the value of structured and deliberate work-based learning for health professionals. It supports the importance of involving a range of learning experiences (e.g. training courses, work-based learning) in lifelong or continuing education (Pennbrant and Svensson, 2018). Whilst much of the continuing education literature is focussed on evaluating learning that is achieved through structured educational interventions, the praxis course described in this paper differs from these approaches as it required students to choose the focus and activities for their own learning. As a result of participation in the praxis course, individual, team and organisational learning were evident.

Work-based learning is student-centred and focussed on process rather than content, demanding skills in critical reflection, goal-setting, project management and an understanding of learning processes. It is therefore important to facilitate students to successfully assume responsibility for their learning and self-manage the work-based learning process. A focus on self-directed and self-managed learning highlighted that the student participants did not always possess the skills to critically reflect upon their practice and develop appropriate learning goals, activities and outcomes. Given that reflective skills are increasingly described as essential attributes of competent health professionals, and are included in undergraduate education and registration processes (Mann et al., 2009), this gap was surprising. Making the time for reflective practice and opportunities to discuss issues with others (e.g. university staff, 
workplace supervisors and colleagues) were seen as important in supporting reflective practice. As a result of the challenges experienced by students, additional planning time and activities have been built into the praxis course. Students are required to contact the course convenor several months before they wish to complete the praxis course and complete a student selfawareness questionnaire, a career action plan and schedule a number of conversations with the course convenor.

Along with difficulties in reflecting upon their learning needs, and as a consequence of this difficulty, students struggled to articulate learning activities and the outcomes they expected. Choosing learning goals, reflecting on current practices and areas of learning need, and articulation of how they would achieve learning within the workplace context were important. Whilst learning contracts have been utilised in educational settings for many years (Doncaster, 2000, Sandle, 2010) there is a paucity of research regarding the skills and supports required to facilitate completion of an effective learning plan (Costley and Abukari, 2010). This study identified the learning plan as an important element of the praxis course, guiding student and supervisor engagement in learning activities and promoting a shared understanding of work contexts and professional learning goals. However, the development of a learning plan was generally experienced as a time-consuming and stressful process. This study suggests that workplace learning requires specialised skills to support and guide practitioners through the process. Our results demonstrate that the previous experience of the praxis convenors (e.g. counselling training, case management experience) were important in appropriately supporting students. As we did not anticipate that this element of the learning experience would be so important or challenging, further research is needed to which examine preparation activities and resources that can best support the development of a workplace learning plan.

Partnerships were recognised as a key aspect of the praxis course, facilitating commitment to the work-based learning process, promoting collaborative reflection and enabling the development of a supportive learning environment. Constructive relationships with convenors and mentors were established through flexible and responsive communication and an ability to positively challenge students to step outside their comfort zone and engage in new or challenging areas of practice. Whilst the 'teacher-student' relationship was important, of equal, if not more, importance were workplace relationships between the student and their workplace supervisors, clients and colleagues. Transformations in these workplace relationships through the adoption of a student identity created opportunities for the emergence of new understandings and practices that reshaped the professional identities of the students. 
A strength of the work-based learning course was flexibility. The praxis course was able to respond to the needs of a diverse group of mental health practitioners, working in a variety of settings. The familiarity of coursework created barriers for students establishing a shared understanding of the purpose, design and processes of the praxis course and they required significant support to complete this task. To better prepare students, the course website has been updated to include clearer information about the praxis course requirements, specific work-based learning resources and example learning plans. Praxis convenors recognised that different models of teaching were required to effectively facilitate work-based learning and identified a range of skills needed to successfully convene the praxis course. Convenors also remarked on the challenges of the work-based teaching role, including inadequate resourcing of work-based learning opportunities, workload issues, and limited support with managing student safety.

\section{Conclusions}

Work-based learning can be effective in improving the relevance of education through engagement with real-life work issues and contexts. The outcomes of this study supported the value of providing postgraduate students with work-based learning opportunities, resulting in the application of new or advanced skills, within their individual professional work roles. Work-based learning is very different to coursework and the importance of developing strong partnerships and shared ownership of the curriculum cannot be understated. Planning of workbased learning opportunities is student-led and thus requires specific skills (e.g., reflection and goal-setting) to be successful. Consequently, it is equally important to acknowledge the different skills and resources required to effectively support work-based learning. This study is therefore important, because it contributes valuable findings to the literature, providing insights into the student experience of postgraduate work-based learning and the impact of this learning on professional practice. Further investigation into the processes and practices of work-based learning for postgraduate students across a diverse range of disciplines is recommended.

\section{Declarations}

\section{Ethics approval and consent to participate}

Ethics approval was obtained from the Griffith University Human Research Ethics Committee (HSV/02/13/HREC). 


\section{Competing interests}

The authors declare that they have no competing interests.

\section{Funding}

Partial funding for this study was provided from a Griffith University Learning and Teaching grant.

\section{Acknowledgements}

The authors would like to thank the study participants for their stories and reflections which formed the basis of this study. 


\section{Table 1 Semi-structured student interview schedule}

1. I am really interested in hearing about your experiences of participating in the mental health praxis course and would like to ask some questions about your experiences.

a) What were some of your expectations when enrolling in this course?

b) How were your expectations met?

c) Were there any different outcomes/experiences from your original expectations?

2. I would like to talk about developing your learning goals/plan

a) How did you go about choosing your learning plan goals?

b) What was the experience of developing the learning plan like?

c) How useful was the learning plan in shaping your experience and/or learning?

3. I am interested in talking about your work

a) What (if any) impact has this course had on your work performance?

b) How do you think the workplace viewed your participation in the mental health praxis course?

c) What sort of future learning experiences would you be interested in pursuing?

4. I am interested in exploring what factors facilitated or restricted your learning

a) Can you tell me a little bit about some of your personal attributes which may have impacted on your learning?

b) What about the qualities of your supervisor/mentor or aspects of this process which impacted on your learning?

c) What about your workplace?

5. I am interested in talking about course design of the mental health praxis course.

a) What do you see as the strengths of the current mental health praxis course?

b) What do you see as the weaknesses of the current mental health praxis course?

c) What would you like to see change about the mental health praxis course?

6. Is there anything else that you would like to say in relation to anything that we have talked about today? (Check understanding and if any points require clarification). 
Table 2 Student participant demographic profile

\begin{tabular}{|c|c|c|}
\hline Participant & Age & Background \\
\hline Natalie & 43 & $\begin{array}{l}\text { Natalie worked as a social worker and mental health case manager } \\
\text { in a State Government Health Service in regional Queensland. Her } \\
\text { praxis learning goals focussed on the use of medication within } \\
\text { mental health care, how prescribing decisions were made by } \\
\text { medical staff, and the side effects and impact of medication use on } \\
\text { the consumers she worked with. She had a particular interest in } \\
\text { how the prescription of clozapine (an antipsychotic medication) } \\
\text { was managed within the health service in which she worked and } \\
\text { how consumers experienced this service. }\end{array}$ \\
\hline Emma & 36 & $\begin{array}{l}\text { As an occupational therapist and case manager, Emma worked in a } \\
\text { State Government Health Service in regional New South Wales. } \\
\text { Emma had an interest in learning about Acceptance and } \\
\text { Commitment Therapy (ACT) and increasing her skills in utilising } \\
\text { this therapy in her practice. Emma's primary goal was to introduce } \\
\text { ACT for young mental health consumers within a group setting. } \\
\text { Emma also had a praxis goal of incorporating mindfulness activities } \\
\text { within her own practice. }\end{array}$ \\
\hline Lauren & 43 & $\begin{array}{l}\text { Lauren worked within management in a small non-government } \\
\text { organisation in metropolitan Queensland. Laura developed a } \\
\text { number of praxis goals focussed on better understanding around } \\
\text { some of the upcoming Government funding changes and how these } \\
\text { might affect her service. The aim of her praxis goals was to develop } \\
\text { clear plans and processes to build organisational capacity to meet } \\
\text { these changes. }\end{array}$ \\
\hline Chloe & 23 & $\begin{array}{l}\text { Chloe worked as a disability support worker in a non-government } \\
\text { organisation in metropolitan Queensland. Through the praxis, } \\
\text { Chloe aimed to better assist the people she worked with to decrease } \\
\text { or quit smoking and establish an effective quit smoking program } \\
\text { for her organisation. She also wanted to learn more about } \\
\text { appropriate housing options to better support mental health } \\
\text { consumers to maintain their accommodation. During the praxis, } \\
\text { Chloe worked with an external housing organisation to enhance her } \\
\text { skills and meet these goals. }\end{array}$ \\
\hline Katie & 31 & $\begin{array}{l}\text { As a registered nurse, Katie had recently taken on a new role as a } \\
\text { mental health and drug and alcohol liaison worker within an } \\
\text { Emergency Department of a large hospital in metropolitan Victoria. } \\
\text { Her praxis goals were concerned with identifying an appropriate } \\
\text { alcohol and drug screening tool for mental health assessment staff } \\
\text { to utilise with all consumers presenting at the Emergency }\end{array}$ \\
\hline
\end{tabular}




\begin{tabular}{|l|l|l|}
\hline & & $\begin{array}{l}\text { Department. As a result of her praxis, Katie aimed to implement } \\
\text { new practices in which screening for drug and alcohol would } \\
\text { become a standard assessment process used by all members of the } \\
\text { assessment team. }\end{array}$ \\
\hline Alyssa & 28 & $\begin{array}{l}\text { As a solo social work practitioner within a small non-government } \\
\text { organisation in regional Queensland, Alyssa had recently been } \\
\text { supporting the families of consumers who had died by suicide. } \\
\text { Alyssa identified that she was not experienced in providing this } \\
\text { type of support and her praxis goals reflected her desire to learn } \\
\text { new skills in this practice area. She also aimed to develop new } \\
\text { skills in working with young people with a mental illness who were } \\
\text { at risk of suicide. }\end{array}$ \\
\hline Sarah & $\begin{array}{l}\text { Sarah had a work history as a non-government mental health } \\
\text { support worker, but had recently been appointed to a social worker } \\
\text { position in a State Government Health Service in metropolitan New } \\
\text { South Wales. As this was a new role for Sarah, her praxis goals } \\
\text { were focussed on developing skills in the clinical aspects of care } \\
\text { required in this role. Her goals included becoming proficient in } \\
\text { mental state examinations and providing assertive case } \\
\text { management practices. }\end{array}$ \\
\hline
\end{tabular}

Table 3 Themes and subthemes

\begin{tabular}{|l|l|}
\hline Themes & Subthemes \\
\hline $\begin{array}{l}\text { Planning for work-based learning is } \\
\text { hard but important }\end{array}$ & $\begin{array}{l}\text { - The journey from resistance to } \\
\text { celebration } \\
\text { - Difficulty deciding on a goal } \\
\text { - Planning is the key to success }\end{array}$ \\
\hline $\begin{array}{l}\text { The significance of learning in the } \\
\text { workplace }\end{array}$ & $\begin{array}{l}\text { - Time for reflection } \\
\text { - Learning requires partnerships }\end{array}$ \\
\hline The academic side of the story & $\begin{array}{l}\text { - Isolation and the impact of on-line study } \\
\end{array}$ \\
& - Ensuring safety \\
& \\
\hline
\end{tabular}




\section{References}

Billet, S. 2002. Critiquing workplace learning discourses: Participation and continuity at work. Studies in the Education of Adults [Online], 34.

Billet, S. 2004. Workplace participatory practices: Conceptualising workplaces as learning environments. Journal of Workplace Learning, 16, 312-324.

Blaschke, L.M. 2012. Heutagogy and lifelong learning: A review of heutagogical practice and self-determined learning. The International Review of Research in Open and Distributed Learning, 13, 56-71.

Boud, D. \& Solomon, N. 2001. Work-based learning: a new higher education?, McGraw-Hill Education, U.K.

Bravenboer, D. 2018. The unexpected benefits of reflection: a case study in university-business collaboration. Journal of Work-Applied Management, 10, 50-62.

Clarke, D. J. \& Copeland, L. 2003. Developing nursing practice through work-based learning. Nurse Education in Practice, 3, 236-244.

Costley, C. and Abukari, A. 2010. Impact Study: A study prepared for the higher education academy. Middlexsex University, London, U.K.

Costley, C. and Abukari, A. 2015. The impact of work-based research projects at postgraduate level. Journal of Work-Applied Management, 7, 3-14

Costley, C. and Stephenson, J. 2008. "Building doctorates around individual candidates professional experience", in Boud, D. and Lee, A. (Eds.) Changing practices of doctoral education. Routledge, London, U.K.

Council of Australian Governments. 2009. National Action Plan for Mental Health 2006-2011: Second Progress Report Covering Implementation to 2007-08, Commonwealth Government, Canberra, Australia.

Doncaster, K. 2000. Learning agreements: their function in work-based programmes at Middlesex University. Education \& Training 42, 349-355.

Eikeland, O. 2013. Symbiotic Learning Systems: Reorganizing and Integrating Learning Efforts and Responsibilities Between Higher Educational Institutions (HEIs) and Work Places. Journal of the Knowledge Economy, 4, 98-118.

Forsetlund, L., Bjørndal, A., Rashidian, A., Jamtvedt, G., O’Brien, M. A., Wolf, F., Davis, D., Odgaard-Jensen, J. \& Oxman, A. D. 2009. Continuing education meetings and workshops: effects on professional practice and health care outcomes. Cochrane Database of Systematic Reviews (Online), CD003030.

Garnett, J. 2016. Work-based learning: A critical challenge to the subject discipline structures and practices of higher education. Higher Education, Skills and Work-Based Learning, $6,305-314$.

Gruppen, L. D., Mangruldar, R. S. \& Kolars, J. C. 2012. The promise of competency-based education in the health professions for improving global health. Human Resources for Health, 10, 43.

Happell, B. 2006. Psychiatric/mental health nursing education in Victoria, Australia: Barriers to specialization. Archives of Psychiatric Nursing, 20, 76-81.

Hewlett, E. and Moran, V. 2014. Making Mental Health Count: The social and economic costs of neglecting mental helath care, OECD Health Policy Studies, OECD Publishing, Paris, France.

Higgs, J., Loftus, S. and Trede, F. 2010. "Education for Future Practice”, in Higgs, J., Fish, D., Goulter, I., Loftus, S., Reid, J. and Trede, F. (Eds.) Education for Future Practice. Sense Publishers, Rotterdam, Netherlands. 
Jarvis, P. 2009. "Learning to be an expert: Competence development and expertise", in Illeris, K. (ed.) International Perspectives on Competence Development, Routledge, Abingdon, U.K.

Kettle, J. 2013. Flexible Pedagogies: employer engagement and work-based learning. Higher Education, The Higher Education Academy, University of Hull, U.K.

Lester, S., Bravenboer, D and Webb, N. 2016. Work-integrated degrees: Context, engagement, practice and quality. QAA

Lester, S. and Costley, C. 2010. Work-based learning at higher education level: value, practice and critique. Studies in Higher Education, 35, 561-575.

Mann, K., Gordon, J. and Macleod, A. 2009. Reflection and reflective practice in health professions education: a systematic review. Advances in health sciences education : theory and practice, 14, 595-621.

McCormack, B. and Manly, K. 2004. "Evaluating practice development", in Garbett, R., Manley, K. M. N. and McCormack, B. (Eds.) Practice Development in Nursing, Blackwell, U.K.

McCrae, N., Askey-Jones, S. and Laker, C. 2014. Merely a stepping stone? Professional identity and career prospects following postgraduate mental health nurse training. Journal of Psychiatric and Mental Health Nursing, 21, 767-773.

Nottingham, P. 2016. The use of work-based learning pedagogical perspectives to inform flexible practice within higher education. Teaching in Higher Education, 21, 790-806.

Pennbrant, S. and Svensson, L. 2018. Nursing and learning - healthcare pedagogics and workintegrated learning. Higher Education, Skills and Work-Based Learning, 8, 179-194.

Pype, P., Symons, L., Wens, J., Van den Eynden, B., Stes, A. and Deveugele, M. 2014. Health care professionals' perceptions towards lifelong learning in palliative care for general practitioners: a focus group study. BMC Family Practice, 15, 36.

Qualitative Solution and Research 2011. NVivo 11 ed. Qualitative Solution and Research, Doncaster, Australia.

Rhodes, G. and Shiel, G. 2007. Meeting the needs of the workplace and the learner through work-based learning. Journal of Workplace Learning, 19, 173-187.

Roberts, R. and Maylea, C. 2017. "Australian mental health workforce: State and national policy imperatives and implications for workforce development", in 18th International Mental Health Conference proceedings in Gold Coast, Australia, Australian and New Zealand Mental Health Association, pp. 49-61

Saldana, J. 2011. Fundamentals of qualitative research, Oxford University Press, New York, U.S.A.

Sandle, M. 2010. "The strength of the MA by learning contract in the context of lifelong learning", in Trevor, K., Elton, L. and Harland, T. (Eds.) Meeting the Challenges of Change in postgraduate education. Continuum, New York, U.S.A.

Smith, J. A., Flowers, P. and Larkin, M. 2009. Interpretative Phenomenological Analysis: Theory, Method and Research, Sage, London, U.K.

Smith, P. and Preece, D. 2009. Postgraduate work-based learning programmes in English higher education: exploring case studies of organizational practice. Journal of Vocational Education \& Training, 61, 169-182.

Spouse, J. 2001. Work-based learning in health care environments. Nurse Education in Practice, 1, 12-18.

Stewart, V., Campbell, M. and Wheeler, A. J. 2016a. Developing a postgraduate work-based curriculum using an Intervention Mapping Approach. Studies in Continuing Education, $38,1-16$. 
Stewart, V., Crozier, M. and Wheeler, A.J. 2016b. Interprofessional learning issues in postgraduate mental health education. Journal of Social Inclusion [Online], 7. Available: https://josi.journals.griffith.edu.au/index.php/inclusion/article/view/832.

Stewart, V., Fielden, J., Harris, M. and Wheeler, A.J. 2012. Making mental health practitioners workforce ready. The Journal of Mental Health Training, Education and Practice, 7, 124-132.

Zhang, B., Yin, C., David, B., Xiong, Z. and Niu, W. 2016. Facilitating professionals' workbased learning with context-aware mobile system. Science of Computer Programming, 129, 3-19. 